\title{
Decreased staging of differentiated thyroid cancer in patients with chronic lymphocytic thyroiditis
}

\author{
M. Borowczyk ${ }^{1} \cdot$ A. Janicki ${ }^{1}$ - G. Dworacki ${ }^{2}$ - E. Szczepanek-Parulska ${ }^{1} \cdot$ M. Danieluk ${ }^{1} \cdot$ J. Barnett $^{1} \cdot$ M. Antonik ${ }^{1}$. \\ M. Kałużna ${ }^{1} \cdot$ B. Bromińska ${ }^{1} \cdot$ R. Czepczyński ${ }^{1}$ - M. Bączyk ${ }^{1} \cdot$ K. Ziemnicka $^{1} \cdot$ M. Ruchała $^{1}$
}

Received: 21 November 2017 / Accepted: 24 March 2018 / Published online: 4 April 2018

(c) The Author(s) 2018

\begin{abstract}
Purpose The biological association between chronic lymphocytic thyroiditis (CLT) and differentiated thyroid cancer (DTC) has not been elucidated yet. The aim of the study was to assess whether the presence of CLT exerts any influence on clinical or histological presentation of DTC.

Methods Nine hundred and seven consecutive patients with DTC treated in the years 1998-2016 were divided into two groups according to the presence or absence of concomitant CLT. The statistical differences were analysed.

Results Out of 907 patients included in the study, 331 were diagnosed with DTC and CLT (studied group), while 576 patients with DTC but without CLT constituted a control group. The distribution of papillary and follicular thyroid cancer did not differ. In CLT group, the prevalence of pT1 was greater than for pT2-pT4 DTC $(P=0.0003$; OR $=1.69,95 \%$ CI $1.27-2.24$ ) compared to controls ( 68.3 vs. $56.1 \%$, respectively). The presence of multifocal lesions was similar. The thyroid capsule infiltration without extrathyroidal invasion $(P<0.0001$; OR $=0.21,95 \%$ CI $0.14-0.31)$ was more frequent in the studied group, unlike extracapsular invasion, which was significantly more often present in patients with DTC but without CLT $(P=0.004 ; \mathrm{OR}=1.66 ; 95 \% \mathrm{CI} 1.17-2.34)$ as well as nodal involvement $(P=0.048$; OR $=0.65,95 \%$ CI $0.42-0.99)$.

Conclusions The collected data indicate a protective role of CLT in preventing the spread of the DTC. The presence of CLT might limit tumour growth to the primary site.
\end{abstract}

Keywords Chronic lymphocytic thyroiditis · Hashimoto's thyroiditis · Differentiated thyroid cancer · Inflammation · Cancer

\section{Introduction}

The number of patients with differentiated thyroid carcinoma (DTC), which comprises papillary thyroid carcinoma (PTC) and follicular thyroid carcinoma (FTC) with their variants, is continuously growing [1-3]. Differentiated thyroid carcinoma characterizes with the fastest growing number of new cancer diagnoses worldwide [4], with the incidence increase up to tenfold in the last 30 years [5, 6]. It is still a matter of debate whether this phenomenon may be attributed

K. Ziemnicka

kaziem@ump.edu.pl

1 Department of Endocrinology, Metabolism and Internal Diseases, Poznan University of Medical Sciences, 49, Przybyszewskiego Street, 60-355 Poznan, Poland

2 Department of Clinical Immunology, Poznan University of Medical Sciences, 5D, Rokietnicka Street, 60-806 Poznan, Poland to increased morbidity or is the consequence of better diagnostics. However, the latter explanation seems to play a more important role [7].

The global increase has also been observed in the rate of diagnosis of chronic lymphocytic thyroiditis (CLT) or socalled Hashimoto's thyroiditis, which according to International Classification of Diseases (ICD-10) characterizes with diffuse infiltration of the thyroid gland with lymphocytes, resulting in progressive destruction of the parenchyma and hypothyroidism. The incidence of CLT is now estimated to be $0.3-1.5$ per 1000 individuals worldwide, making it one of the most common endocrine disorders $[8,9]$. What is worth noticing, currently relatively younger patients are diagnosed, if compared to the past [10]. Moreover, CLT is the most common cause of hypothyroidism in iodine-sufficient countries $[11,12]$ and is also regarded the most frequent autoimmune disease [13]. Whether the relationship between an increase in the incidence of CLT and DTC is such of cause and effect remains to be elucidated. 
The idea of the relationship between the chronic inflammation and cancer is not new, as the observation supporting this conclusion that leukocytes can be found in neoplastic tissue, was made already by Rudolf Virchow more than a century ago [14]. Since then, chronic esophagitis has been linked to oesophageal cancer, inflammatory bowel disease to colorectal cancer and primary biliary cirrhosis to hepatocellular carcinoma $[15,16]$. Differentiated thyroid cancer is the most commonly diagnosed concomitant disease in patients with CLT referred for thyroidectomy [17], with coexistence rate ranging from 0.5 to $58 \%$ [17-20]. On the other hand, in the group of patients with PTC, the occurrence rate of CLT is 2.8 times higher compared to patients with benign thyroid diseases [21] The universal background further supports the link of the two conditions, i.e., relationship to ionizing radiation exposure and dietary iodine, as well as some molecular features, i.e., RET/PTC rearrangements and point mutations of the $R A S$ and $B R A F$ genes [20]. These observations suggest that patients with CLT might be prone towards the development of PTC [22]. Although the association between CLT and DTC is suggested since 1955 [23], it is still debatable whether CLT indeed predisposes patients to the development of DTC [24]. Moreover, data on the impact of CLT on clinical and pathological parameters of DTC are ambiguous [25]. There is a vivid discussion ongoing in the current medical literature whether the coexistence of CLT and DTC influences the course of the latter and if the patients with CLT have the more favourable impact with regards to the behaviour of diagnosed DTC. Gathered data are conflicting, while research on homogeneous population are lacking [25-27]. Many previous studies demonstrated less aggressive disease at presentation, a better outcome in patients with DTC and CLT compared to those with DTC and no CLT, or both [28-31], whereas other results did not support these conclusions [32-34].

Therefore, in our study performed on the highly homogeneous group of patients, we aimed to assess whether the presence of CLT exerts any influence on clinical or histological presentation of DTC.

\section{Materials and methods}

We retrospectively analysed the occurrence of CLT in a cohort of patients diagnosed with DTC to determine its influence on the disease.

\section{Patients' characteristics}

We retrospectively analysed 907 consecutive patients treated at a single tertiary care department of endocrinology, diagnosed with DTC. The analysis covers the data collected between 1998 and 2016. According to the revised World
Health Organization criteria from 2004, 837 patients had the diagnosis of PTC or its variants, while 70 patients were diagnosed with FTC or its variants [35]. The group consisted of 801 women and 106 men. All patients were Caucasians. The median age at diagnosis was 49 years, ranging from 18 to 84 .

Clinical records and results of histopathological examinations of the resected specimen following thyroidectomy performed in all patients were analysed.

Patients with histopathological features suggestive of Graves' disease or with a known previous diagnosis of Graves' were excluded from the study.

The following data were recorded from patients' files: gender, age at diagnosis, histological type and subtype of DTC (PTC and variants, FTC and variants), tumour size, multifocality, capsular invasion without extrathyroidal extension and histopathological staging (pTNM).

\section{Parameters assessed and pathological definitions}

The diagnosis of CLT was confirmed by histopathological examination of the specimen from thyroidectomy, performed at the moment of DTC diagnosis and included the presence of diffuse lymphocytic infiltrate, oxyphilic cells, and the formation of primary and secondary lymphoid follicles [33]. Hashimoto's thyroiditis, focal lymphocytic thyroiditis, and expansion of single lymphoid follicles have been discriminated. Hashimoto's thyroiditis was defined as extensive diffuse lymphocytic infiltration (DLT) with the formation of many secondary lymphoid follicles having prominent germinal centres that are destructive to thyroid. Limited lymphocytic infiltration without alterations of the thyroid follicular cells characterized focal lymphocytic thyroiditis (FLT) [36].

We also discriminated samples with the presence of single lymphoid follicles (SLF) in a mild lymphocytic inflammatory background without signs of thyroid destruction as a stage of a non-advanced immune reaction. The last two (FLT and SLF) were considered to be the less advanced thyroiditis. Figure 1 shows the examples of histopathological pictures. Tumours were supposed to be multifocal when two or more foci were found. In case of multifocality, the size of the tumour was concerned as the size of the most significant focus. The staging procedures were performed according to the American Joint Committee on Cancer TNM staging system (7th Edition) [37], as described by Girardi et al. [25]. Qualified pathologists assessed all histopathological specimens obtained during thyroidectomies.

\section{Statistical analysis}

The parameters were recorded and entered into a dedicated database. To summarize the collected data, descriptive analysis was used. Data were tested by D'Agostino and Pearson omnibus normality test to determine the normality of continuous 


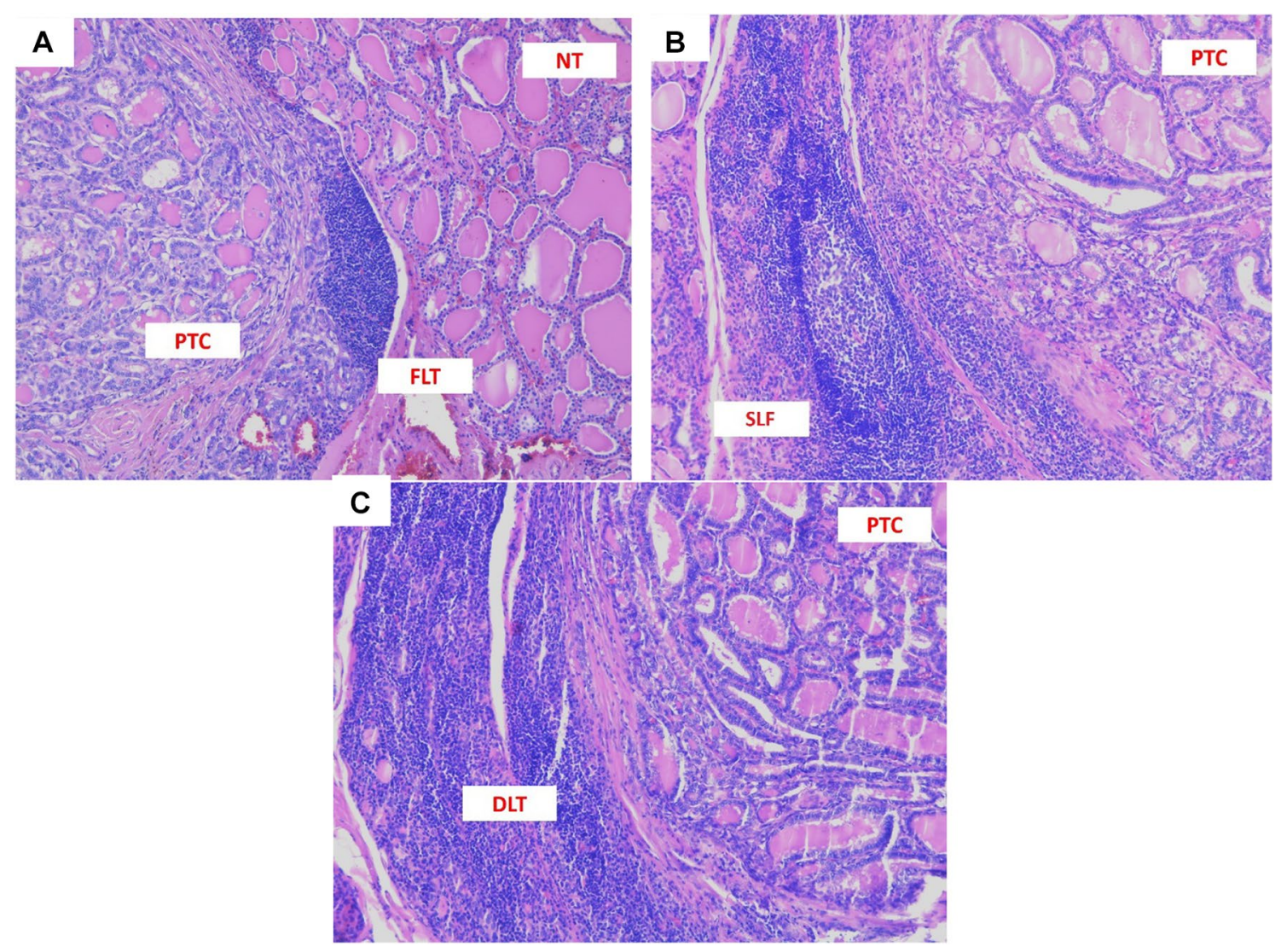

Fig. 1 Histopathological picture of papillary thyroid carcinoma (PTC) coexisting with different types of lymphocytic infiltration at magnification 100x. a PTC with focal lymphocytic thyroiditis (FLT). b PTC with single lymphoid follicles (SLF). c PTC with Hashimoto's thyroiditis (diffuse lymphocytic thyroiditis-DLT) variables. Variables that were found to be continuous were expressed as means and respective standard deviations. Data that were found to be non-continuous were expressed as median and minimum-maximum values.

To compare differences between groups, we used the Chisquare test or Fisher's exact test $(2 \times 2$ contingency table $)$, as appropriate for categorical variables. Interval data were compared with the use of the Mann-Whitney $U$ test since the data did not follow normal distribution.

A $P$ value of less than 0.05 was regarded as significant. Statistical analyses were performed with StatSoft Statistica v10.0 and Analyse-it for Microsoft Excel v3.53 software.

\section{Data availability}

The datasets analysed during the current study are available from the corresponding author on reasonable request.

\section{Results}

A group of 907 patients diagnosed with differentiated thyroid cancer were included in the study. The analysis of histopathological assessment of the specimens from thyroidectomies allowed for the discrimination between patients with DTC and concomitant CLT $(n=331)$ and the control group of patients with DTC but without CLT $(n=576)$.

Two hundred and seven patients fulfilled the criteria of Hashimoto's thyroiditis diagnosis (62.5\% of all CLT), 69 had single lymphoid follicles (SLF) (20.8\%), 37 presented focal lymphocytic thyroiditis (11.2\%), and 18 (5.5\%) had both FLT and SLF.

Patients in the study group, with DTC and CLT, differed significantly concerning gender distribution and age at diagnosis in comparison with control group. They were 
Table 1 Patients' characteristics

\begin{tabular}{|c|c|c|c|c|}
\hline Characteristic & $\begin{array}{l}\text { Patients with DTC } \\
\text { and CLT } \\
n=331\end{array}$ & $\begin{array}{l}\text { Patients with DTC and } \\
\text { without CLT } \\
n=576\end{array}$ & $P$ value & $\begin{array}{l}\text { OR (Odds ratio) with } \\
95 \% \text { CI (confidence } \\
\text { interval) }\end{array}$ \\
\hline Female/Male, $n(\%)$ & $312 / 19(94 / 6)$ & $489 / 87(85 / 15)$ & $<0.0001$ & $2.92(1.74-4.90)$ \\
\hline Median age at diagnosis, years (range) & $45(18-79)$ & $50(18-84)$ & $<0.0001$ & - \\
\hline Multifocality, $n(\%)$ & $68(20.5)$ & $89(15.5)$ & 0.0557 & $1.41(1.00-2.01)$ \\
\hline Capsule invasion, $n(\%)$ & $66(19.9)$ & $83(14.4)$ & 0.033 & $1.48(1.04-2.11)$ \\
\hline Extracapsular invasion, $n(\%)$ & $55(16.6)$ & $143(24.8)$ & 0.004 & $0.60(0.43-0.85)$ \\
\hline Nodal (N) involvement, $n(\%)$ & $32(9.7)$ & $81(14.1)$ & 0.048 & $0.65(0.42-0.99)$ \\
\hline Mean tumour size, mm (range) & $15.7(1-250)$ & $12.1(1-95)$ & 0.618 & - \\
\hline Tumour diameter $\leq 10 \mathrm{~mm}, n(\%)$ & $180(54.4)$ & $305(53.0)$ & 0.285 & $1.06(0.81-1.39)$ \\
\hline Papillary thyroid carcinoma, $n(\%)$ & 307 (92.7) & $530(92.0)$ & 0.796 & $1.11(0.66-1.85)$ \\
\hline Classical, $n(\%)$ & $233(70.4)$ & $414(71.9)$ & 0.703 & $0.93(0.69-1.25)$ \\
\hline Follicular, $n(\%)$ & $50(15.1)$ & $80(13.9)$ & 0.694 & $1.10(0.75-1.62)$ \\
\hline Classical/follicular, $n(\%)$ & $11(3.3)$ & $19(3.3)$ & 1.000 & $1.01(0.47-2.14)$ \\
\hline Oxyphilic, $n(\%)$ & $9(2.7)$ & $15(2.6)$ & 1.000 & $1.05(0.45-2.42)$ \\
\hline Follicular/oxyphilic, $n(\%)$ & $4(1.2)$ & $2(0.3)$ & 0.199 & $3.51(0.64-19.27)$ \\
\hline Follicular thyroid carcinoma, $n(\%)$ & $24(7.3)$ & $46(8.0)$ & 0.796 & $0.90(0.54-1.50)$ \\
\hline Classical, $n(\%)$ & $16(4.9)$ & $34(5.9)$ & 0.583 & $0.71(0.24-2.07)$ \\
\hline Oncocytic (Hürthle cell) variant, $n(\%)$ & $8(2.4)$ & $12(2.1)$ & & \\
\hline
\end{tabular}

Italics represents statistically significant values

younger at diagnosis (median age: 45 vs. 50 years) and female:male ratio was much higher (16.4 vs. 5.5 respectively). Patients' characteristics are presented in Table 1.

Chronic lymphocytic thyroiditis did not affect the multifocality of the tumours. Neither their size was changed in CLT patients. However, the thyroid capsule invasion was significantly more often present in patients in the studied group in comparison with the control group ( $\mathrm{OR}=1.48$, range 1.04-2.11). The less advanced forms of chronic thyroiditis (e.g., FLT or SLF) were correlated with more advanced tumour stage (Table 2).

No statistically significant association could be determined between any of the histopathological types and subtypes of DTC and the presence of concomitant CLT. We found that in comparison with the control group, patients with DTC and CLT presented a lower staging of thyroid cancer tumour. The prevalence of pT1 stage was greater than pT2-pT4 in the group of patients in the studied group (68.3\% pT1) compared to controls (56.1\% pT1) that differs statistically at $P$ value $=0.0003(\mathrm{OR}=1.69,95 \%$ CI $1.27-2.24)$ (Fig. 2). We also found that extracapsular invasion (pT3 and pT4) was significantly more often present in patients with DTC but without CLT in comparison with patients with CLT and DTC (OR $=1.66,95 \% \mathrm{CI} 1.17-2.34, P=0.004)$. The staging of the tumour was lower in patients with CLT (OR $=0.6,95 \%$ CI $0.43-0.83, P=0.003)$. Patients with CLT were also at significantly lower risk of nodal involvement
$(\mathrm{OR}=0.65$, range $0.42-0.99)$. The risk was also higher in the less advanced forms of chronic thyroiditis.

Table 2 demonstrates patients' and tumours' characteristics in different types of lymphocyte infiltration.

To describe the impact of each parameter on tumour staging, we performed univariate logistic regression analysis which showed that the protective factors against higher tumour staging (pT2-pT4) were female sex, papillary thyroid cancer type (in opposition to follicular thyroid cancer) and the co-occurrence of chronic lymphocytic thyroiditis, regardless of its variant. Particular correlations are shown in Table 3.

Multivariate logistic regression confirmed also the role of CLT in advanced tumour staging risk stratification. Logistic regression model showed that capsule infiltration and FTC increased $(\mathrm{OR}=0.21$ and $\mathrm{OR}=0.23, P<0.0001)$, while $\mathrm{PTC}$ and $\mathrm{CLT}(\mathrm{OR}=4.29$ and $\mathrm{OR}=1.69, P<0.0001)$ diminished the risk of higher tumour staging similarly to the results of OR obtained by $2 \times 2$ contingency table.

\section{Discussion}

The results of our study demonstrate in the largest reported to date cohort of subjects, the possible protective role of CLT in preventing the spread of the tumour by limiting tumour growth to the primary site. Both immunological and genetic mechanisms might contribute to this phenomenon. 
Table 2 Patients' and tumours' characterization due to the type of thyroid inflammation

\begin{tabular}{|c|c|c|c|c|}
\hline Characteristic & $\begin{array}{l}\text { Focal lymphocytic } \\
\text { thyroiditis (FLT) } \\
n=37\end{array}$ & $\begin{array}{l}\text { Single lymphoid follicles } \\
\text { without thyroid destruction } \\
\text { (SLF) } \\
n=69\end{array}$ & $\begin{array}{l}\text { Focal lymphocytic } \\
\text { thyroiditis and SLF } \\
n=18\end{array}$ & $\begin{array}{l}\text { Hashimoto's thyroiditis } \\
n=207\end{array}$ \\
\hline Female/male, $n(\%)$ & $35 / 2(95 / 5)$ & $65 / 4(92 / 6)$ & $18 / 0(100 / 0)$ & $194 / 13(94 / 6)$ \\
\hline Median age at diagnosis, years (range) & $50(21-79)$ & $43(18-72)$ & $41(27-62)$ & $45(18-79)$ \\
\hline Multifocality, $n(\%)$ & $11(29.7)^{\mathrm{a}, \mathrm{c}}$ & $8(11.6)^{\mathrm{a}, \mathrm{b}}$ & $6(33.3)^{\mathrm{a}, \mathrm{c}}$ & $43(20.8)^{\mathrm{a}, \mathrm{b}, \mathrm{c}}$ \\
\hline Capsule invasion, $n(\%)$ & $9(24.3)^{\mathrm{a}, \mathrm{b}}$ & $21(30.4)^{b}$ & $2(11.1)^{\mathrm{a}, \mathrm{b}}$ & $34(16.4)^{\mathrm{a}}$ \\
\hline Extracapsular invasion, $n(\%)$ & $6(16.2)^{\mathrm{a}, \mathrm{c}}$ & $16(23.2)^{b}$ & $3(16.7)^{\mathrm{a}, \mathrm{c}}$ & $29(14.0)^{\mathrm{a}, \mathrm{c}}$ \\
\hline Mean tumour size, mm (range) & $26.7(2-250)$ & $9.2(1-120)$ & $17.9(1-90)$ & $8.2(1-150)$ \\
\hline Tumour diameter $\leq 10 \mathrm{~mm}, n(\%)$ & $22(59.5)$ & $36(52.2)$ & $10(55.6)$ & $112(54.1)$ \\
\hline Nodal (N) involvement, $n(\%)$ & $7(18.9)^{\mathrm{a}}$ & $9(13.0)^{\mathrm{a}}$ & $1(5.6)^{b}$ & $15(7.2)^{\mathrm{b}}$ \\
\hline Papillary thyroid carcinoma, $n(\%)$ & $36(97.3)$ & $64(92.8)$ & $17(94.4)$ & $190(91.8)$ \\
\hline Classical, $n(\%)$ & $29(78.4)$ & $40(58.0)$ & $13(72.2)$ & $151(72.9)$ \\
\hline Follicular, $n(\%)$ & $6(16.2)$ & $17(24.6)$ & $4(22.2)$ & $23(11.1)$ \\
\hline Classical/follicular, $n(\%)$ & 0 & $3(4.3)$ & 0 & $8(3.9)$ \\
\hline Oxyphilic, $n(\%)$ & 0 & $3(4.3)$ & 0 & $6(2.9)$ \\
\hline Follicular/oxyphilic, $n(\%)$ & $1(2.7)$ & $1(1.4)$ & 0 & $2(1.0)$ \\
\hline Follicular thyroid carcinoma, $n(\%)$ & $1(2.7)$ & $5(7.2)$ & $1(5.6)$ & $17(8.2)$ \\
\hline Classical, $n(\%)$ & $1(2.7)$ & $3(4.3)$ & 0 & $11(5.3)$ \\
\hline Oncocytic (Hürthle Cell) Variant, $n(\%)$ & 0 & $2(2.9)$ & $1(5.6)$ & $6(2.9)$ \\
\hline Localization in the right lobe, $n(\%)$ & $26(70.3)^{\mathrm{a}}$ & $33(47.8)^{b}$ & $10(55.6)^{\mathrm{a}, \mathrm{b}}$ & $105(50.7)^{\mathrm{b}}$ \\
\hline Localization in the left lobe, $n(\%)$ & $6(16.2)^{\mathrm{a}}$ & $28(40.6)^{b}$ & $6(33.3)^{\mathrm{a}, \mathrm{b}}$ & $85(41.1)^{\mathrm{b}}$ \\
\hline Localization in both lobes, $n(\%)$ & $5(13.5)$ & $8(11.6)$ & $2(11.1)$ & $17(8.2)$ \\
\hline
\end{tabular}

a,b,c-groups followed by the same letter do not differ statistically significantly

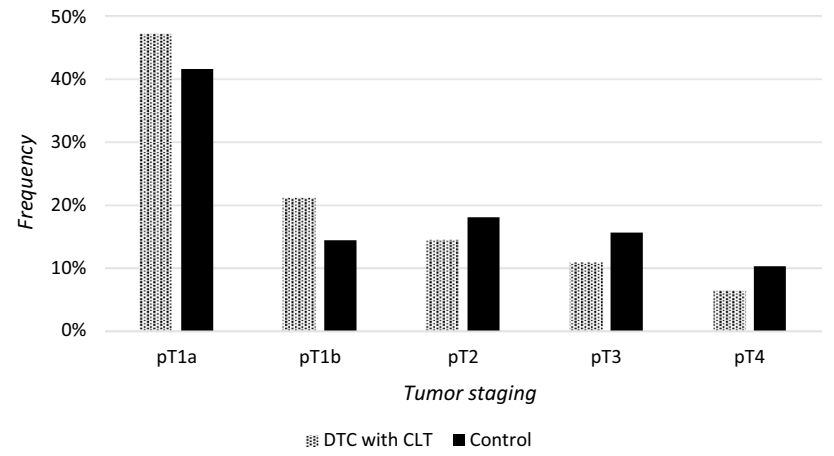

Fig. 2 Tumour staging in analysed groups of DTC patients

An immunological link between DTC and CLT has been confirmed in many studies, however, their causal and temporal relationship is still not elucidated. Whether PTC develops despite immune reaction or whether CLT develops because of cross-reacting antitumour immunity, remains unclear [38].

The results of our research, as the majority of studies reported in a meta-analysis performed by Girardi et al. [25], showed a protective effect of lymphocytic thyroiditis on thyroid cancer clinical picture and prognosis [39].
In our study, the co-occurrence of CLT in DTC was found to be associated with lower tumour staging, lower risk of extracapsular invasion, and nodal involvement. Although the presence of multifocal lesions was similar in both groups, the thyroid capsule invasion without extrathyroidal extension was more frequent in patients with CLT. The findings are supported by different studies [22, 25, 40]. The collected data may indicate a protective role of CLT in the prevention of the tumour spread, while the presence of CLT might limit tumour growth to the primary site. More indolent clinical course in patients with DTC and CLT compared to those with DTC alone, including lower recurrence rates and higher overall survival rates, has already been suggested [39].

The vital role of cancer microenvironment is a subject of ongoing discussions. The protective role of CLT against the spread of DTC may be due to the participation of CD4+, CD8+, CD201+, TH17 and regulatory T cells (Treg) what was suggested by Cunha et al. [41].

Co-occurrence of CLT and PTC may also be linked with chronic stimulation of the thyroid by elevated TSH, which may initiate or promote the growth of thyroid neoplasm [42, 43].

An immunological link between CLT and DTC also lies in thyroglobulin and $\mathrm{TgAb}$ antibodies as it represents the primary target antigens for cellular cytotoxic and humoral 
Table 3 Univariate logistic regression analysis of higher tumour stage risk factors

\begin{tabular}{|c|c|c|c|c|}
\hline Characteristic & $\begin{array}{l}\text { Patients with pT1 DTC } \\
n=549\end{array}$ & $\begin{array}{l}\text { Patients with } \\
\text { pT2-pT4 DTC } \\
n=358\end{array}$ & $P$ value & $\begin{array}{l}\text { OR (Odds Ratio) with } 95 \% \text { CI } \\
\text { (Confidence Interval) for lower } \\
\text { staging }\end{array}$ \\
\hline Female/Male, $n(\%) n(\%)$ & $496 / 53(90 / 10)$ & $305 / 53(85 / 15)$ & 0.020 & $1.63(1.08-2.44)$ \\
\hline Median age at diagnosis, years (range) & $49(18-80)$ & $50(18-84)$ & 0.817 & - \\
\hline Multifocality, $n(\%)$ & $105(19.1)$ & $52(14.5)$ & 0.088 & $1.39(0.97-2.00)$ \\
\hline Capsule infiltration, $n(\%)$ & $44(8.0)$ & $105(29.3)$ & $<0.0001$ & $0.21(0.14-0.31)$ \\
\hline Nodal (N) involvement, $n(\%)$ & $35(6.4)$ & $78(21.8)$ & $<0.0001$ & $0.24(0.16-0.37)$ \\
\hline Papillary thyroid carcinoma, $n(\%)$ & $529(96.4)$ & $308(86.0)$ & $<0.0001$ & $4.29(2.51-7.35)$ \\
\hline Classical, $n(\%)$ & $413(75.2)$ & $234(65.4)$ & 0.495 & $1.13(0.81-1.57)$ \\
\hline Follicular, $n(\%)$ & $86(15.7)$ & $44(12.3)$ & 0.489 & $1.17(0.79-1.73)$ \\
\hline Classical/follicular, $n(\%)$ & $15(2.7)$ & $15(4.2)$ & 0.176 & $0.57(0.27-1.18)$ \\
\hline Oxyphilic, $n(\%)$ & $13(2.4)$ & $12(3.4)$ & 0.293 & $0.62(0.28-1.38)$ \\
\hline Follicular/oxyphilic, $n(\%)$ & $2(0.4)$ & $3(0.8)$ & 0.363 & $0.39(0.06-2.32)$ \\
\hline Follicular thyroid carcinoma, $n(\%)$ & $20(3.6)$ & $50(14.0)$ & $<0.0001$ & $0.23(0.14-0.40)$ \\
\hline Classical, $n(\%)$ & $13(2.4)$ & $36(10.1)$ & 0.576 & $0.72(0.24-2.19)$ \\
\hline Oncocytic (Hürthle Cell) Variant, $n(\%)$ & $7(1.3)$ & $14(3.9)$ & & \\
\hline Chronic lymphocytic thyroiditis & $226(41.2)$ & $105(29.3)$ & 0.0003 & $1.69(1.27-2.24)$ \\
\hline Hashimoto's thyroiditis & $140(25.5)$ & $67(18.7)$ & 0.808 & $0.92(0.57-1.49)$ \\
\hline Focal lymphocytic thyroiditis (FLT) & $27(4.9)$ & $10(2.8)$ & 0.578 & $1.29(0.60-2.77)$ \\
\hline Single lymphoid follicles (SLT) & $45(8.2)$ & $24(6.7)$ & 0.562 & $0.84(0.48-1.47)$ \\
\hline FLT and SLT & $14(2.6)$ & $4(1.1)$ & 0.445 & $1.67(0.54-5.20)$ \\
\hline
\end{tabular}

Italics represents statistically significant values

immune reactions in both chronic lymphocytic thyroiditis and differentiated thyroid cancer [38].

Patients with DTC coexisting with CLT significantly differed also regarding age and gender distribution from those with DTC without CLT. They were much younger (approximately 5 years) and had a higher female predominance (over twofold). The findings remain in accordance with studies of Singh et al. [31], Loh et al. [29] and Ahn et al. [39], who reported that PTC patients with CLT were, respectively, 2, 3 or 5 years younger than those without CLT. These may raise an additional bias of the study - the finding of smaller tumours in this category could be indeed due the shorter time to progression. Previous research also confirmed that women were more prone to be diagnosed with DTC in the course of CLT $[39,44]$. The latter may be linked to general female predominance in thyroid autoimmune diseases [45].

One of the factors limiting the interpretation of our findings is a selection bias, which should be taken into consideration before conclusions are derived. The observed lower staging of DTC, when concomitant with CLT, may be found due to earlier diagnosis of DTC in patients with CLT.

It has been previously suggested that the protective phenomenon of CLT in PTC stems from the immunologically derived destruction of the thyroid tissue by CLT. Kimura et al. reported that IL-1 secreted by the infiltrating lymphocytes in CLT might have exerted an anti-tumourigenic action in some cancer cells differentiation and replication, what may explain the inhibition of human thyroid cancer cell growth in patients with concomitant CLT and DTC [46].

To prevent selection bias and to limit confounding environmental factors, as a study group we have chosen mostly homogenous (4.7\% non-ethnic Poles within Poland), ranking seventh in a study of 159 countries worldwide and third in Europe [2].

In conclusion, the results of our study confirm that the presence of CLT may have a significant protective role in a reduced volume of a tumour and capsule infiltration, lowering the chance for more advanced stages of DTC. The presence of advanced CLT may limit the tumour growth to the primary site. Comprehensive analysis of immunological, genetic and environmental factors, which may contribute to the observation, is required.

Authors' contribution $\mathrm{KZ}$ and GD conceived the idea of the study. $\mathrm{MB}^{*}$ (MB* refers to Martyna Borowczyk), GD, ESP, and KZ contributed to the design of the research. MB*, AJ, MD, JB, MA, MK, BB, $\mathrm{RC}$, and $\mathrm{MB}$ were involved in data collection. $\mathrm{MB}^{*}, \mathrm{GD}, \mathrm{ESP}$, and $\mathrm{KZ}$ analysed and interpreted the data. $\mathrm{MB}^{*}$ performed statistical analyses and prepared tables. MB*, AJ, GD, ESP, MD, JB, MA, KZ, and MR wrote or edited the manuscript. All authors approved the final version of the paper.

Funding This research did not receive any specific Grant from any funding agency in the public, commercial or not-for-profit sector. 


\section{Compliance with ethical standards}

Conflict of interest All authors report no potential conflict of interest.

Ethical approval The study was approved by the Bioethical Committee of Poznan University of Medical Sciences. All procedures performed in study involving human participants were in accordance with the ethical standards of the institutional and national research committee and with the 1964 Helsinki declaration and its later amendments.

Informed consent Informed consent was obtained from all individual participants included in the study for patients' study participation and publication of identifying information and images.

Open Access This article is distributed under the terms of the Creative Commons Attribution 4.0 International License (http://creativeco mmons.org/licenses/by/4.0/), which permits unrestricted use, distribution, and reproduction in any medium, provided you give appropriate credit to the original author(s) and the source, provide a link to the Creative Commons license, and indicate if changes were made.

\section{References}

1. Haugen BR, Alexander EK, Bible KC, Doherty GM, Mandel SJ, Nikiforov YE, Pacini F, Randolph GW, Sawka AM, Schlumberger M, Schuff KG, Sherman SI, Sosa JA, Steward DL, Tuttle RM, Wartofsky L (2016) 2015 American Thyroid Association Management guidelines for adult patients with thyroid nodules and differentiated thyroid cancer: the American Thyroid Association guidelines task force on thyroid nodules and differentiated thyroid cancer. Thyroid 26(1):1-133. https://doi.org/10.1089/ thy. 2015.0020

2. Kilfoy BA, Zheng T, Holford TR, Han X, Ward MH, Sjodin A, Zhang Y, Bai Y, Zhu C, Guo GL, Rothman N, Zhang Y (2009) International patterns and trends in thyroid cancer incidence, 1973-2002. Cancer Causes Control 20(5):525-531. https://doi. org/10.1007/s10552-008-9260-4

3. La Vecchia C, Malvezzi M, Bosetti C, Garavello W, Bertuccio P, Levi F, Negri E (2015) Thyroid cancer mortality and incidence: a global overview. Int J Cancer 136(9):2187-2195. https://doi. org/10.1002/ijc.29251

4. Wiltshire JJ, Drake TM, Uttley L, Balasubramanian SP (2016) Systematic review of trends in the incidence rates of thyroid cancer. Thyroid 26(11):1541-1552. https://doi.org/10.1089/ thy. 2016.0100

5. Ferlay J, Steliarova-Foucher E, Lortet-Tieulent J, Rosso S, Coebergh JW, Comber H, Forman D, Bray F (2013) Cancer incidence and mortality patterns in Europe: estimates for 40 countries in 2012. Eur J Cancer 49(6):1374-1403. https://doi.org/10.1016/j. ejca.2012.12.027

6. Morris LG, Sikora AG, Tosteson TD, Davies L (2013) The increasing incidence of thyroid cancer: the influence of access to care. Thyroid 23(7):885-891. https://doi.org/10.1089/ thy.2013.0045

7. Kitahara CM, Sosa JA (2016) The changing incidence of thyroid cancer. Nat Rev Endocrinol 12(11):646-653. https://doi. org/10.1038/nrendo.2016.110

8. Davies L, Welch HG (2006) Increasing incidence of thyroid cancer in the United States, 1973-2002. JAMA 295(18):2164-2167. https://doi.org/10.1001/jama.295.18.2164

9. Golden SH, Robinson KA, Saldanha I, Anton B, Ladenson PW (2009) Clinical review: prevalence and incidence of endocrine and metabolic disorders in the United States: a comprehensive review. J Clin Endocrinol Metab 94(6):1853-1878. https://doi. org/10.1210/jc.2008-2291

10. Benvenga S, Trimarchi F (2008) Changed presentation of Hashimoto's thyroiditis in North-Eastern Sicily and Calabria (Southern Italy) based on a 31-year experience. Thyroid 18(4):429-441. https://doi.org/10.1089/thy.2007.0234

11. Vanderpump MP (2011) The epidemiology of thyroid disease. $\mathrm{Br}$ Med Bull 99:39-51. https://doi.org/10.1093/bmb/ldr030

12. McLeod DS, Cooper DS (2012) The incidence and prevalence of thyroid autoimmunity. Endocrine 42(2):252-265. https://doi. org/10.1007/s12020-012-9703-2

13. Jacobson DL, Gange SJ, Rose NR, Graham NM (1997) Epidemiology and estimated population burden of selected autoimmune diseases in the United States. Clin Immunol Immunopathol 84(3):223-243

14. Virchow R (1956) Standpoints in scientific medicine, 1877. Bull Hist Med 30(6):537-543

15. Balkwill F, Mantovani A (2001) Inflammation and cancer: back to Virchow? Lancet 357(9255):539-545. https://doi.org/10.1016/ S0140-6736(00)04046-0

16. Franks AL, Slansky JE (2012) Multiple associations between a broad spectrum of autoimmune diseases, chronic inflammatory diseases and cancer. Anticancer Res 32(4):1119-1136

17. Caturegli P, De Remigis A, Chuang K, Dembele M, Iwama A, Iwama S (2013) Hashimoto's thyroiditis: celebrating the centennial through the lens of the Johns Hopkins hospital surgical pathology records. Thyroid 23(2):142-150. https://doi. org/10.1089/thy.2012.0554

18. Latina A, Gullo D, Trimarchi F, Benvenga S (2013) Hashimoto's thyroiditis: similar and dissimilar characteristics in neighboring areas. Possible implications for the epidemiology of thyroid cancer. PLoS One 8(3):e55450. https://doi.org/10.1371/journ al.pone. 0055450

19. Feldt-Rasmussen U, Rasmussen AK (2010) Autoimmunity in differentiated thyroid cancer: significance and related clinical problems. Hormones (Athens) 9(2):109-117

20. Cunha LL, Ferreira RC, Marcello MA, Vassallo J, Ward LS (2011) Clinical and pathological implications of concurrent autoimmune thyroid disorders and papillary thyroid cancer. J Thyroid Res 2011:387062. https://doi.org/10.4061/2011/387062

21. Lee JH, Kim Y, Choi JW, Kim YS (2013) The association between papillary thyroid carcinoma and histologically proven Hashimoto's thyroiditis: a meta-analysis. Eur J Endocrinol 168(3):343349. https://doi.org/10.1530/EJE-12-0903

22. Iliadou PK, Effraimidis G, Konstantinos M, Grigorios P, Mitsakis P, Patakiouta F, Pazaitou-Panayiotou K (2015) Chronic lymphocytic thyroiditis is associated with invasive characteristics of differentiated thyroid carcinoma in children and adolescents. Eur J Endocrinol 173(6):827-833. https://doi.org/10.1530/EJE-14-1046

23. Dailey ME, Lindsay S, Skahen R (1955) Relation of thyroid neoplasms to Hashimoto disease of the thyroid gland. AMA Arch Surg 70(2):291-297

24. Paparodis R, Imam S, Todorova-Koteva K, Staii A, Jaume JC (2014) Hashimoto's thyroiditis pathology and risk for thyroid cancer. Thyroid 24(7):1107-1114. https://doi.org/10.1089/ thy. 2013.0588

25. Girardi FM, Barra MB, Zettler CG (2015) Papillary thyroid carcinoma: does the association with Hashimoto's thyroiditis affect the clinicopathological characteristics of the disease? Braz $\mathbf{J}$ Otorhinolaryngol 81(3):283-287. https://doi.org/10.1016/j.bjorl .2014.04.006

26. Kim HG, Kim EK, Han KH, Kim H, Kwak JY (2014) Pathologic spectrum of lymphocytic infiltration and recurrence of papillary thyroid carcinoma. Yonsei Med J 55(4):879-885. https://doi. org/10.3349/ymj.2014.55.4.879 
27. Matsubayashi S, Kawai K, Matsumoto Y, Mukuta T, Morita T, Hirai K, Matsuzuka F, Kakudoh K, Kuma K, Tamai H (1995) The correlation between papillary thyroid carcinoma and lymphocytic infiltration in the thyroid gland. J Clin Endocrinol Metab 80(12):3421-3424. https://doi.org/10.1210/jcem.80.12.8530576

28. Dvorkin S, Robenshtok E, Hirsch D, Strenov Y, Shimon I, Benbassat CA (2013) Differentiated thyroid cancer is associated with less aggressive disease and better outcome in patients with coexisting Hashimotos thyroiditis. J Clin Endocrinol Metab 98(6):24092414. https://doi.org/10.1210/jc.2013-1309

29. Loh KC, Greenspan FS, Dong F, Miller TR, Yeo PP (1999) Influence of lymphocytic thyroiditis on the prognostic outcome of patients with papillary thyroid carcinoma. J Clin Endocrinol Metab 84(2):458-463. https://doi.org/10.1210/jcem.84.2.5443

30. Kashima K, Yokoyama S, Noguchi S, Murakami N, Yamashita H, Watanabe S, Uchino S, Toda M, Sasaki A, Daa T, Nakayama I (1998) Chronic thyroiditis as a favorable prognostic factor in papillary thyroid carcinoma. Thyroid 8(3):197-202. https://doi. org/10.1089/thy.1998.8.197

31. Singh B, Shaha AR, Trivedi H, Carew JF, Poluri A, Shah JP (1999) Coexistent Hashimoto's thyroiditis with papillary thyroid carcinoma: impact on presentation, management, and outcome. Surgery 126(6):1070-1076 (discussion 1076-1077b)

32. Kebebew E, Treseler PA, Ituarte PH, Clark OH (2001) Coexisting chronic lymphocytic thyroiditis and papillary thyroid cancer revisited. World J Surg 25(5):632-637. https://doi.org/10.1007/ s002680020165

33. Kim EY, Kim WG, Kim WB, Kim TY, Kim JM, Ryu JS, Hong SJ, Gong G, Shong YK (2009) Coexistence of chronic lymphocytic thyroiditis is associated with lower recurrence rates in patients with papillary thyroid carcinoma. Clin Endocrinol (Oxf) 71(4):581-586. https://doi.org/10.1111/j.1365-2265.2009.03537 . $\mathrm{x}$

34. Jeong JS, Kim HK, Lee CR, Park S, Park JH, Kang SW, Jeong JJ, Nam KH, Chung WY, Park CS (2012) Coexistence of chronic lymphocytic thyroiditis with papillary thyroid carcinoma: clinical manifestation and prognostic outcome. J Korean Med Sci 27(8):883-889. https://doi.org/10.3346/jkms.2012.27.8.883

35. DeLellis RA, Lloyd RV, Heitz PU, Eng C (2004) World health organization classification of tumours. Pathology and genetics of tumours of endocrine organs. IARC Press, Lyon

36. Focal lymphocytic thyroiditis. PathologyOutlines.com website. http://www.pathologyoutlines.com/topic/thyroidfocallymphocy tic.html. Accessed 3 Sept 2017
37. Edge SB, Compton CC (2010) The American Joint Committee on cancer: the 7th edition of the AJCC cancer staging manual and the future of TNM. Ann Surg Oncol 17(6):1471-1474. https://doi. org/10.1245/s10434-010-0985-4

38. Ehlers M, Schott M (2014) Hashimoto's thyroiditis and papillary thyroid cancer: are they immunologically linked? Trends Endocrinol Metab 25(12):656-664. https://doi.org/10.1016/j. tem.2014.09.001

39. Ahn D, Heo SJ, Park JH, Kim JH, Sohn JH, Park JY, Park SK, Park J (2011) Clinical relationship between Hashimoto's thyroiditis and papillary thyroid cancer. Acta Oncol 50(8):1228-1234. https://doi.org/10.3109/0284186X.2011.602109

40. Bircan HY, Koc B, Akarsu C, Demiralay E, Demirag A, Adas M, Alis H, Kemik O (2014) Is Hashimoto's thyroiditis a prognostic factor for thyroid papillary microcarcinoma? Eur Rev Med Pharmacol Sci 18(13):1910-1915

41. Cunha LL, Morari EC, Guihen AC, Razolli D, Gerhard R, Nonogaki S, Soares FA, Vassallo J, Ward LS (2012) Infiltration of a mixture of immune cells may be related to good prognosis in patients with differentiated thyroid carcinoma. Clin Endocrinol (Oxf) 77(6):918-925. https://doi.org/10.111 1/j.1365-2265.2012.04482.x

42. Medenica S, Radojevic N, Stojkovic M, Nedeljkovic-Beleslin B, Savic S, Ciric J, Trbojevic B, Zarkovic M (2015) Autoimmunity and thyrotropin level in developing thyroid malignancy. Eur Rev Med Pharmacol Sci 19(15):2824-2829

43. McConahey WM (1972) Hashimoto's thyroiditis. Med Clin North Am 56(4):885-896

44. Repplinger D, Bargren A, Zhang YW, Adler JT, Haymart M, Chen $\mathrm{H}$ (2008) Is Hashimoto's thyroiditis a risk factor for papillary thyroid cancer? J Surg Res 150(1):49-52. https://doi.org/10.1016/j. jss.2007.09.020

45. Quintero OL, Amador-Patarroyo MJ, Montoya-Ortiz G, RojasVillarraga A, Anaya JM (2012) Autoimmune disease and gender: plausible mechanisms for the female predominance of autoimmunity. J Autoimmun 38(2-3):J109-J119. https://doi. org/10.1016/j.jaut.2011.10.003

46. Kimura H, Yamashita S, Namba H, Tominaga T, Tsuruta M, Yokoyama N, Izumi M, Nagataki S (1992) Interleukin-1 inhibits human thyroid carcinoma cell growth. J Clin Endocrinol Metab 75(2):596-602. https://doi.org/10.1210/jcem.75.2.1322431 